\title{
Стимулированное излучение в диапазоне 10-31 мкм в гетероструктурах с квантовыми ямами HgTe / CdHgТе с диэлектрическим и «фононным» волноводами
}

\author{
C.В. Морозов \\ Институт физики микроструктур РАН, Нижний Новгород, 603950, Россия
}

DOI 10.34077/RCSP2021-29

Одной из актуальных и быстро развивающихся задач современной физики полупроводников является разработка компактных источников когерентного ТГц излучения. Лучшие параметры генерации ТГц излучения имеют квантово-каскадные лазеры (ККЛ). Однако, существует спектральный диапазон $\lambda=20-60$ мкм, не покрываемый ККЛ за счет полосы остаточных лучей $\mathrm{A}_{\text {III }} \mathrm{B}_{\mathrm{V}}$ полупроводников, на основе которых изготавливается подавляющее большинство ККЛ. Межзонные полупроводниковые лазеры представляют собой простую альтернативу ККЛ.

Одной из перспективных для таких источников узкозонных полупроводниковых систем являются узкозонные гетероструктуры с квантовыми ямами (КЯ) $\mathrm{HgTe} / \mathrm{CdHgTe}$, энергия ТО фонона в которых лежит в диапазоне $\lambda=60$ - 90 мкм. Современная МПЭ позволяет выращивать $\mathrm{HgCdTe}$ структуры с низкой остаточной концентрацией примесей и дефектов, из-за чего каналы безызлучательной рекомбинации на примесях и дефектах насыщаются уже при умеренных интенсивностях накачки [1]. В дополнение, КЯ $\mathrm{HgTe} / \mathrm{CdHgTe}$ имеют сильно непараболические законы дисперсии электронов и дырок, квазисимметричные в окрестности $\mathrm{k}=0$, что позволяет существенно подавить безызлучательную оже-рекомбинацию и увеличить её порог от нескольких единиц до 40-50 мэВ [2]. Несмотря на то, что ранее СИ в материалах $\mathrm{HgCdTe}$ было получено лишь на длинах волн вплоть до 5.3 мкм, использование узких КЯ позволяет существенно продвинуться в длинноволновый диапазон спектра.

В данной работе в волноводных гетероструктурах с $\mathrm{HgTe} / \mathrm{HgCdTe}$ КЯ, выращенных методом МПЭ на полуизолирующей $\mathrm{GaAs}$ (013) подложке с ZnTe и CdTe

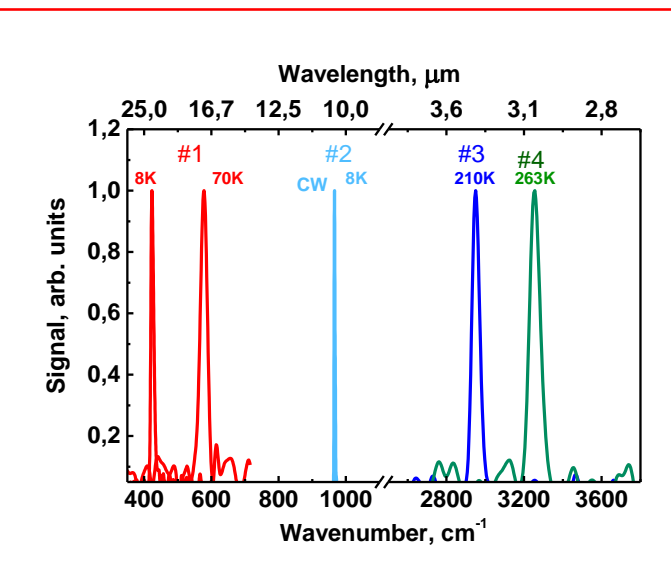

Рис.1. - Спектры СИ при различных температурах (сплошные кривые), полученные при импульсном (\# $1, \lambda_{\text {exс }}=$ 10,6 мкм; образцы \# 3, \# $4 \lambda_{\text {ехс }}=1,5$ мкм) и $\mathrm{cw}\left(\# 2, \lambda_{\text {exc }}=0,9\right.$ мкм) оптическом возбуждении.

буферами, было получено стимулированное излучение $($ СИ) при импульсной оптической накачке на длинах волн вплоть до 25 мкм. В области меньших длин волн $\lambda \sim 10$ мкм пороговая интенсивность накачки составляла всего $120 \mathrm{BT} / \mathrm{cm}^{2}\left(\lambda_{\text {ехс }} \sim 2\right.$ мкм), и СИ было получено даже при непрерывной накачке $\left(\lambda_{\text {exс }} \sim 0.9\right.$ мкм). В рамках работы рассчитана пороговая энергия оже-рекомбинации для серии КЯ $\mathrm{HgTe} / \mathrm{Cd}_{\mathrm{x}} \mathrm{Hg}_{1-\mathrm{x}} \mathrm{Te}$ с одинаковой $\mathrm{Eg} \sim 70$ мэВ (соответствует $\lambda \sim 18$ мкм), но различной толщиной КЯ и долей $\mathrm{Cd}$ в барьерах. Продемонстрирована немонотонная зависимость пороговой энергии ожерекомбинации от доли $\mathrm{Cd}$ в барьерах, имеющая максимум при $\mathrm{x}_{\mathrm{Cd}}=0.5-0.7$. Показано, что применение узких КЯ $\mathrm{HgTe} / \mathrm{CdHgTe} \mathrm{c} \mathrm{оптимальным} \mathrm{составом} \mathrm{барьеров} \mathrm{позволяет} \mathrm{подавить} \mathrm{оже-рекомбинацию} \mathrm{и}$ продвинуться по длине волны СИ в диапазон $\lambda>25$ мкм.

\section{Лumepamypa}

[1] Morozov, S. V., et al. Appl. Phys. Lett. 104(7), 072102 (2014).

[2] S.V. Morozov, et al., Appl. Phys. Lett., 2017. 111(19): p. 192101. 